\title{
Relative importance of meteorological and geographical factors in the distribution of Fasciola hepatica infestation in farmed sheep in Qinghai province, China
}

\author{
Hongyu Qin, Xiang Gao, Hongbin Wang, and Jianhua Xiao* \\ Department of Veterinary Surgery, Northeast Agricultural University, Harbin, Heilongjiang 150030, PR China
}

Received 9 September 2016, Accepted 7 December 2016, Published online 21 December 2016

\begin{abstract}
Fasciola hepatica is an important trematode parasite of economic importance that infests sheep and cattle worldwide. We conducted a detailed investigation into the spatial distribution of $F$. hepatica infestation in farmed sheep in Qinghai (Wutumeiren) province, Mainland China. Mathematical modelling was used to assess the interrelationships between meteorological and geographical factors and the risk of $F$. hepatica infestation across the province. A capture enzyme-linked immunosorbent assay (ELISA) test (MM3-SERO) was used to detect F. hepatica infestation. A niche model based on the maximum entropy method (MaxEnt) was used to estimate the influence of meteorological and geographical factors on the observed spatial distribution of $F$. hepatica infestation. Results of jackknife analysis indicated that temperature, precipitation, solar radiation, digital elevation and slope were associated with the occurrence of $F$. hepatica infestation, and that infestation rates were significantly higher among animals from districts with a high percentage of grassland habitat. The findings indicate that meteorological and geographical factors may be important variables affecting the distribution of $F$. hepatica infestation and should be taken into account in the development of future surveillance and control programmes for fascioliasis.
\end{abstract}

Key words: Fasciola hepatica, Parasite, Meteorological and geographical factors, Risk analysis, Prediction map.

\begin{abstract}
Résumé - Importance relative des facteurs météorologiques et géographiques dans la distribution de l'infestation à Fasciola hepatica chez les moutons d'élevage dans la province de Qinghai en Chine. Fasciola hepatica est un important trématode parasite, d'importance économique, qui infeste les moutons et les bovins dans le monde entier. Nous avons mené une enquête détaillée sur la répartition spatiale de l'infestation par $F$. hepatica chez des moutons d'élevage dans la province de Qinghai (Wutumeiren), en Chine continentale. La modélisation mathématique a été utilisée pour évaluer les interrelations entre les facteurs météorologiques et géographiques et le risque d'infestation par $F$. hepatica dans toute la province. Un test ELISA de capture (MM3-SERO) a été utilisé pour détecter l'infestation par $F$. hepatica. Un modèle de niche basé sur la méthode de l'entropie maximale (Maxent) a été utilisé pour estimer l'influence des facteurs météorologiques et géographiques sur la répartition spatiale observée de l'infestation par $F$. hepatica. Les résultats de l'analyse de Jackknife ont indiqué que la température, les précipitations, le rayonnement solaire, l'élévation numérique et la pente étaient associés à l'apparition d'une infestation par $F$. hepatica et que les taux d'infestation étaient significativement plus élevés chez les animaux provenant de districts où l'habitat des prairies était élevé. Les résultats indiquent que les facteurs météorologiques et géographiques peuvent être des variables importantes affectant la distribution de l'infestation par $F$. hepatica et devraient être pris en compte dans l'élaboration de futurs programmes de surveillance et de lutte contre la fasciolose.
\end{abstract}

\section{Introduction}

Fasciola hepatica (F. hepatica), also known as the common liver fluke, is a parasite that is widespread throughout the world [13]. The species utilizes snails of the Lymnaeidae family as its

\footnotetext{
*Corresponding author: jhxiao1970@163.com
}

intermediate host [15]. Infestation in the primary host, commonly livestock of various species, causes fascioliasis, a disease which has a major economic impact on livestock productivity due to its negative effects on milk yield, meat production and fertility, as well as high mortality rates. It is estimated that fascioliasis infestations in cattle result in annual 
losses of $€ 30$ per cow across the dairy population in Flanders, Belgium, and $€ 299$ per infested cow in Switzerland [3, 30]. Moreover, farmed animal species such as sheep and cattle may play an important role as reservoirs for human fascioliasis infestation in endemic areas [15].

In recent years, fascioliasis has emerged or re-emerged in many countries, both in animal and human populations [14]. This may be due to changes in local climate conditions. Previous studies have indicated that both $F$. hepatica and its snail host can respond rapidly to variations in environmental conditions [21, 29]. Small increases in temperature and rainfall can extend the window of contamination risk leading to higher transmission and infestation rates [14, 34]. Because Geographic Information Systems (GIS) can rapidly and directly associate climatic and topographical variables with species presence/absence data $[1,24]$, they can be used to make predictions about the distribution of species. On this basis, geographical spatial risk models of fascioliasis have been developed in many countries [6, 17, 34, 35].

In this study, spatial risk analysis was performed by means of the maximum entropy method (MaxEnt) [25]. MaxEnt can generate inferences from limited information about the species presence and has shown high prediction accuracy [18]. Furthermore, it can evaluate the contribution of each environmental factor to the distribution of the species and ultimately produce a predictive distribution map. Thus, it has been extensively used for predicting the potential distributions of plants, animals and insects [5, 26, 33].

The aim of this study was to assess the influence of meteorological and geographical factors on the distribution of $F$. hepatica infestation in sheep, by using the MaxEnt model and data collected from the Qinghai province of mainland China. It is anticipated that the findings will inform the current understanding of the epidemiology of F. hepatica and provide information relevant to the design of more effective control strategies for the eradication of fascioliasis.

\section{Materials and methods}

\section{Study area}

Qinghai province is located in the north of Mainland China. It extends between latitude $31^{\circ} 9^{\prime}$ and $39^{\circ} 19^{\prime} \mathrm{N}$ and longitude $89^{\circ} 35^{\prime}$ and $103^{\circ} 04^{\prime}$ E. Qinghai province has a plateau continental climate. The temperature and rainfall have marked seasonal variation: average temperatures range from $-5.0{ }^{\circ} \mathrm{C}$ to $-10.3{ }^{\circ} \mathrm{C}$ in winter and $10.8{ }^{\circ} \mathrm{C}$ to $19.0^{\circ} \mathrm{C}$ in summer. The majority of the rainfall occurs in the wet season, from June to October. The province has a long dry season from November to May, coinciding with the lowest minimum temperatures. Because of the high altitude of the region, the level of solar radiation is high. Total annual solar radiation can be up to 690,800-753,600 joules per square centimeter. Mountains are mainly distributed in the western parts of the province, and the Qaidam Basin occupies the eastern part of the province. The basin is the main pastoral area because it consists of a large number of lakes and swamps. The grassland area of the province is 40.34 million hectares, which represents $12 \%$ of the total grassland area of Mainland China.

\section{Testing of sheep herds for $F$. hepatica infestation}

Every year from 2012 to 2015, all sheep herds in Qinghai province were tested for $F$. hepatica infestation. Blood samples were collected from sheep $>6$ months of age in every herd, exposure levels were calculated by using percent positivity (PP) values [17]. Herds with a PP value of less than 27 were considered negative for $F$. hepatica infestation. Finally, 84 herds were considered positive for $F$. hepatica infestation in the 4 years. Their geographic coordinates were recorded by using portable GPS (Global Position System) and saved as data points about the infestation presence.

F. hepatica testing was carried out as follows: Blood was collected from sheep on the farm and immediately placed in a cooler. Samples were centrifuged within $12 \mathrm{~h}$ of collection to obtain sera. Serum samples were stored frozen at $-20{ }^{\circ} \mathrm{C}$ and sent within 3 days to the Biology Laboratory of Qinghai University, China, for analysis. Detection of $F$. hepatica was based upon the MM3-SERO capture ELISA test [22]. Firstly, serum samples were diluted to $1 \%$ by addition of $1 \%$ skimmed milk powder and phosphate-buffered saline (PBS) containing $0.2 \%$ Tween-20 (PBS-T). Subsequently, diluted samples were added to 96-well ELISA plates containing either MM3 alone or MM3-Ag complexes and incubated at $37{ }^{\circ} \mathrm{C}$ for $2 \mathrm{~h}$. A peroxidase-conjugated monoclonal antibody to sheep IgG (Sigma-Aldrich) that had been diluted 1:30,000 was added to each well and incubated for $90 \mathrm{~min}$ at $37^{\circ} \mathrm{C}$. O-phenylenediamine (SigmaFast OPD tablets, Sigma-Aldrich) was then added and the incubation continued for $20 \mathrm{~min}$ at room temperature. Finally, $25 \mu \mathrm{L}$ of $3 \mathrm{M} \mathrm{H}_{2} \mathrm{SO}_{4}$ was used to stop the reaction and the optical density (OD) was measured at $492 \mathrm{~nm}$ using a spectrophotometer. The cut-off value was calculated on the basis of OD values obtained from the sera of sheep that had not been exposed to $F$. hepatica infestation.

\section{Meteorological and geographical variables}

Meteorological data for the years 2009-2015 were included in the analysis and obtained from the China Meteorological Data Sharing System (http://data.cma.cn/) [37]. This network provides a high spatial resolution of approximately $1 \mathrm{~km}^{2}$ for gridded climate data across China and has been frequently used for spatial ecological modelling and mapping [8]. In the present analysis, individual years were defined as the period between 1 November of the previous year and 31 October of the present year.

The geographical data came from the "Land Cover Classification Database" of the University of Maryland, United States (http://www.landcover.org/data/landcover/). These data had been produced from satellite data obtained from the Advanced Very High Resolution Radiometer (AVHRR), a cross-track scanning system with five spectral bands having a resolution of $1.1 \mathrm{~km}$ and a frequency of earth scans twice per day. In addition, digital elevation and slope data were 
Table 1. Risk variables inputted into the model.

\begin{tabular}{lll}
\hline Type of variable & \multicolumn{1}{c}{ Name of variable } & Abbreviation \\
\hline Land cover & Water & L1 \\
& Deciduous Needleleaf Forest & L2 \\
& Deciduous Broadleaf Forest & L3 \\
& Theropencedrymion & L4 \\
& Wooded Grassland & L5 \\
& Grassland & L6 \\
& Closed Shrubland & L7 \\
& Open Shrubland & L8 \\
& Cropland & L9 \\
& Bare Ground & L10 \\
& Urban and Built & L11 \\
& Slope & L12 \\
& Digital elevation & L13 \\
& Monthly maximum & M1 \\
& temperature & \\
Meteorological & Monthly minimum & M2 \\
variables & temperature & \\
& Mean monthly temperature & M3 \\
& Monthly temperature range & M4 \\
& Relative humidity & M5 \\
& Rainfall & M6 \\
& Solar radiation & M7 \\
\hline
\end{tabular}

included in the analysis. These data were obtained from the National Geomatics Center of China (http://ngcc.sbsm. gov.cn/). The meteorological, elevation and geographical data were all inputted into a raster map by means of ArcGIS 10.2 software (ESRI, Redlands, CA, USA). Table 1 shows the risk variables inputted into the model.

\section{Predictive modelling}

The MaxEnt model was used to analyse the effect of meteorological and geographical factors on the spatial distribution of $F$. hepatica infestation in sheep in Qinghai province. MaxEnt can make predictions of species distribution based on incomplete data and can estimate the relative importance of each identified risk variable by means of the jackknife test [9]. To develop and test the model produced by this analysis, $75 \%$ of the data were used as training data and the remaining $25 \%$ were used to test the model's predictive ability [36].

Evaluation of the model's performance in predicting the distribution of $F$. hepatica infestation was based on the Area Under the Curve (AUC) of the Receiver Operating Characteristic Curve (ROC), as developed by Peterson et al. [23]. AUC may range from 0.5 to 1 and higher AUC indicates better model performance. Sensitivity, which is also named the true positive rate, can measure the ability to correctly identify diseased sheep. Its value equals the rate of true positive and the sum value of true positive and false negative. Specificity, which is also named the true negative rate, can measure the ability to correctly identify non-diseased sheep. Its value equals the rate of true negative and the sum value of false positive and true negative. The value of the AUC was calculated by R-statistical analysis software, version 2.15.1 [32].

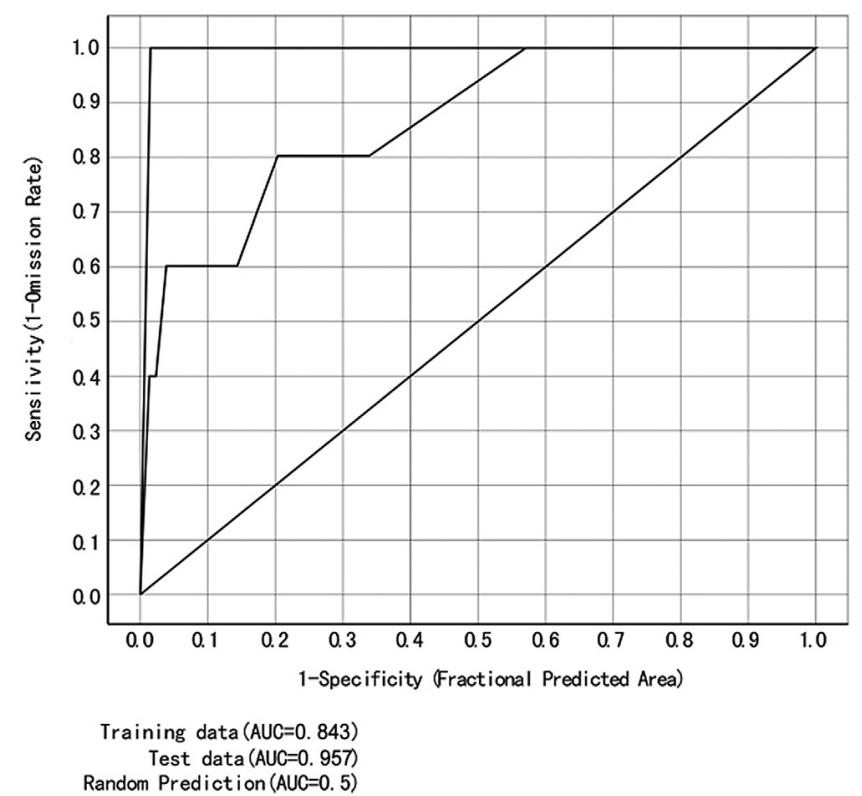

Figure 1. ROC curves produced by the MaxEnt model. AUC values of greater than 0.8 indicate high performance (high predictive ability) of the model.

\section{Results}

\section{Assessment of the accuracy of the predictive model}

A higher AUC indicates better performance and stronger predictive power of the MaxEnt model. The final values of the AUC in the present study were 0.843 and 0.957 , for the training and testing data sets, respectively. This indicates that the predictions made by the MaxEnt model were relatively accurate (Fig. 1).

\section{Relative importance of the variables}

Finally, 84 herds were considered positive for F. hepatica infestation in our survey. These 84 herds mainly distributed in six prefectures of Qinghai province (Table 2). Figure 2 displays the results of the jackknife analysis. These results show that, among the meteorological variables included in the model, mean monthly temperature, precipitation, solar radiation, digital elevation and slope had the most significant effect on the probability of $F$. hepatica infestation, and that $F$. hepatica infestation occurred most frequently in the regions with the highest percentage of grassland.

\section{Prediction map of $\boldsymbol{F}$. hepatica distribution}

Figure 3 displays the potential geographic distribution of F. hepatica infestation as predicted by the MaxEnt program. According to the predicted distribution, the eastern part of Qinghai province carries the highest risk level for $F$. hepatica infestation, extending to the southern and south-western regions of the province. The Qaidam Basin and Qinghai Lake are located in the east of Qinghai province, thus, this region has 


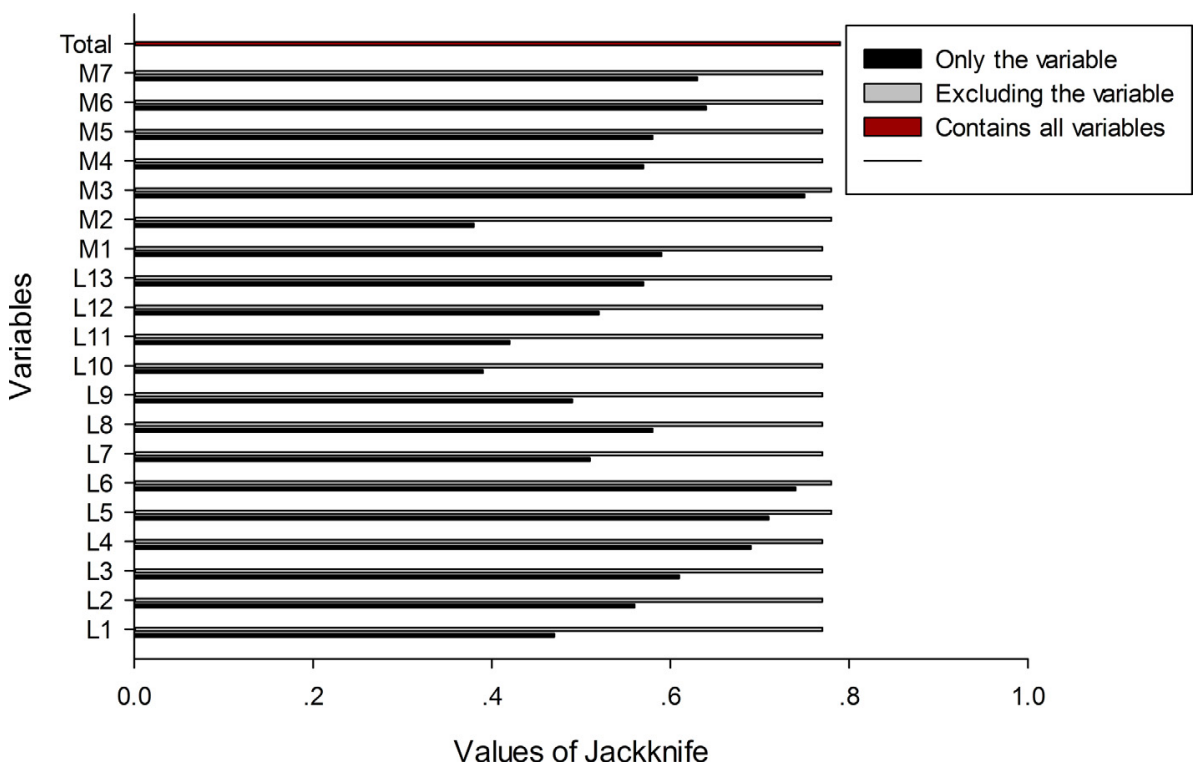

Figure 2. Relative importance of meteorological variables in predicting the probability of $F$. hepatica infestation, as determined by the jackknife analysis. Variables producing higher trainings gain are considered to be more important (more predictive). L1 - Water; L2 - Deciduous Needleleaf Forest; L3 - Deciduous Broadleaf Forest; L4 - Theropencedrymion; L5 - Wooded Grassland; L6 - Grassland; L7 - Closed Shrubland; L8 - Open Shrubland; L9 - Cropland; L10 - Bare Ground; L11 - Urban and Built; L12 - Slope; L13 - Digital elevation; M1 - Monthly maximum temperature; M2 - Monthly minimum temperature; M3 - Mean monthly temperature; M4 - Monthly temperature range; M5 - Relative humidity; M6 - Rainfall; M7 - Solar radiation.

Table 2. The number of F. hepatica infestation positive sheep herds in Qinghai Province.

\begin{tabular}{lccccc}
\hline Prefecture & Total & 2012 & 2013 & 2014 & 2015 \\
\hline Minhe & 10 & 1 & 3 & 4 & 3 \\
Hualong & 7 & 1 & 2 & 5 & 1 \\
Wulan & 16 & 2 & 5 & 6 & 4 \\
Gonghe & 18 & 3 & 7 & 5 & 2 \\
Huzhu & 12 & 3 & 3 & 3 & 1 \\
Gangcha & 13 & 3 & 5 & 1 & \\
Nangqian & 3 & 0 & 2 & 0 \\
\hline
\end{tabular}

Note: Five species distributed in the Hoh Xil, which is a nature reserve and does not belong to any prefecture.

more dense vegetation. Compared with the north-western and central regions, which are mainly mountainous land, the southern and south-western regions of Qinghai province also have lower altitude and a warmer and more humid climate.

\section{Discussion}

The ability of climatic conditions to modulate the extent and intensity of $F$. hepatica infestations is well known [14, 21]. In the present study, the results of the jackknife analysis revealed that temperature, precipitation, solar radiation, digital elevation, slope and grassland may be among the important variables influencing the occurrence of $F$. hepatica infestations in sheep.

Weather conditions can affect the incidence of both F. hepatica itself and its intermediate hosts $[14,20]$. In the case of $F$. hepatica, temperature can have a pronounced influence on cercariae production in the intermediate host, which is a crucial step in the life cycle of trematode worms [7]. Kendall and McCullough [10] demonstrated that F. hepatica ceases development and its cercariae are not liberated from the snail intermediate host when environmental temperatures fall below $10{ }^{\circ} \mathrm{C}$. An analysis by Poulin [27] similarly reported that the rate of cercarial emergence from snail hosts is markedly higher when temperatures are around $20^{\circ} \mathrm{C}$, compared with lower temperatures. This study also indicated that the snail's physiological growth rate, which reflects enzymatic reactions in the snail's body, is doubled or tripled with every $10{ }^{\circ} \mathrm{C}$ increase in temperature.

Rainfall and moisture are necessary for the development of F. hepatica. At the same time, rainfall has a positive effect on the survival and reproduction of the snail intermediate host [19]. At the right level, rainfall can create humid microhabitats which benefit $F$. hepatica, whilst on the other hand, large amounts of rainfall will inhibit $F$. hepatica infestation because it can wash away the parasite larvae separating them from the snail hosts [12, 28]. In a study by Rapsch [34], $210 \mathrm{~mm}$ of 

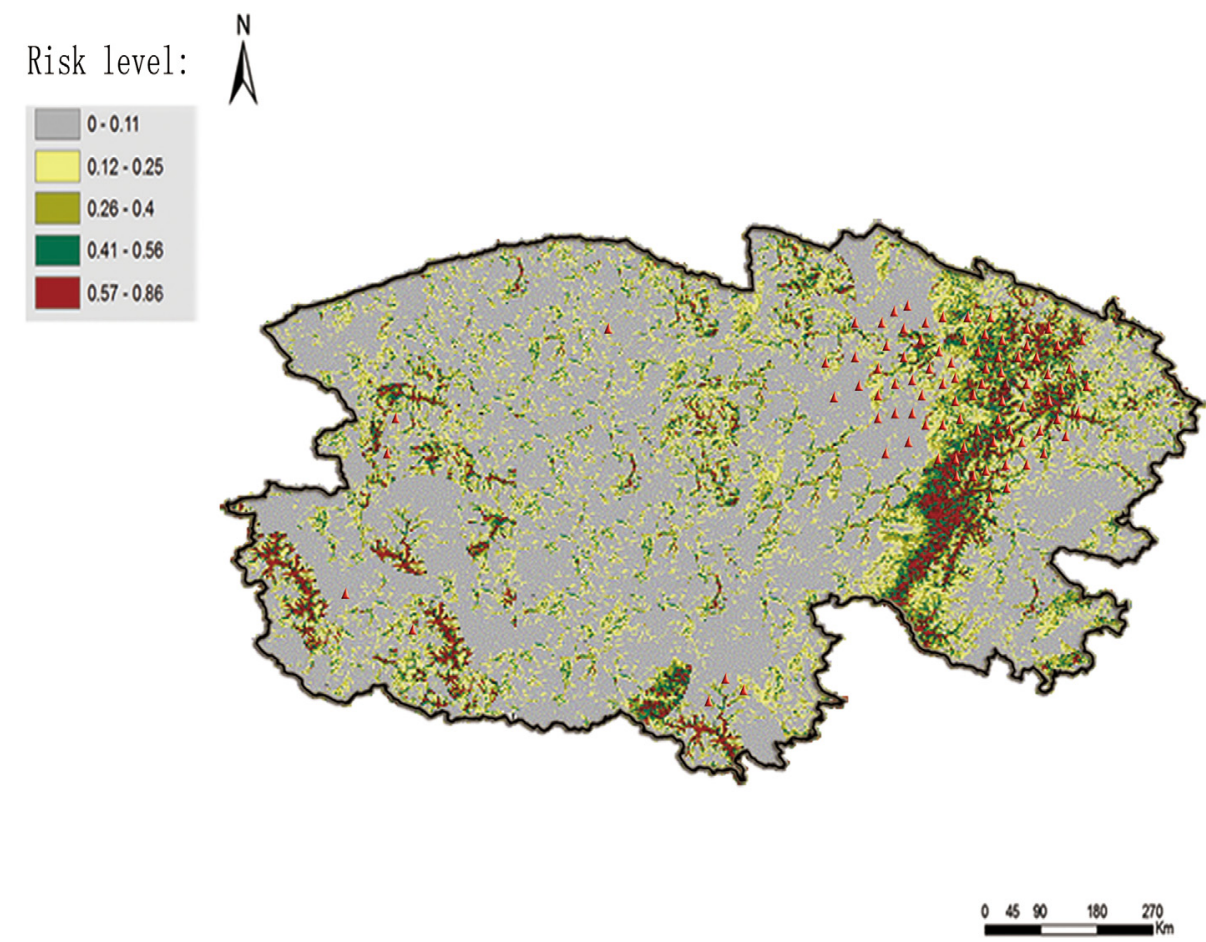

Figure 3. Risk map of F. hepatica infestation predicted by MaxEnt. The highest risk of infestation with F. hepatica is situated in the east of Qinghai province. The red triangles represent the location of sheep herds considered positive for F. hepatica infestation.

rainfall was shown to be a threshold level in this respect. When precipitation goes beyond this value, the risk of $F$. hepatica infestation decreases rapidly. In Qinghai province, annual precipitation ranges from 100 to $180 \mathrm{~mm}$. It would therefore appear that rainfall in this region provides sufficient humidity for the survival of $F$. hepatica and its intermediate host snails.

Solar radiation also showed a positive correlation with the occurrence of $F$. hepatica infestation in the present study. This may be because algae are the major food source of the snail hosts [34] and a high level of solar radiation has a positive effect on the growth rates of algae.

Previous studies have indicated that land supporting dense vegetation carries a high risk of $F$. hepatica infestation [34]. Because soils with dense vegetation, such as grassland, woodland and forest, inherently have low drainage and high water retentive capacities, they tend to support smaller water bodies and water courses which are the preferred habitat of the Lymnaeidae [2, 4, 11]. Compared with grassland, forest and woodland have been shown to confer a lower risk of fascioliasis infestation because of the lower level of solar radiation in these habitat types. Moreover, grassland is typically used for grazing and is thus more likely to be contaminated with the faeces of infested livestock containing F. hepatica eggs [20]. Therefore, grassland with low water permeability and high water retention properties confers a higher risk of $F$. hepatica infestation than other soil types.

According to the prediction maps generated by the present study, the most probable distribution areas for F. hepatica were located in the East of Qinghai province. This may reflect the land use, elevation and slope of the eastern region, which could affect the survival of $F$. hepatica and its intermediate host. The Qaidam Basin occupies the east of the province and has a high concentration of grassland which is a habitat known to have a higher risk of infestation with $F$. hepatica, as discussed above. In addition, because of the low altitudes in the eastern area, average temperatures tend to be higher than in other regions of the province. Warm temperatures in the east may have promoted prolonged survival of $F$. hepatica and its snail hosts [14]. Finally, compared with the hilly lands in the western regions of the province, the lowland eastern areas have a low level of digital elevation, and slope data and drainage in these areas are impeded. Rainfall always exceeds potential transpiration in these areas and thus is beneficial for the luxuriant vegetation and the conservation of smaller water bodies and water courses in these areas [21]. Thus, the environment of the eastern regions of Qinghai province is more suitable for the survival of $F$. hepatica and its intermediate host freshwater snails.

MaxEnt is well known as a presence-only ecological niche model [16]. It can make predictions about species distribution based on limited data and has shown high prediction accuracy [18]. The previously mentioned study by Stockwell [31] indicated that the MaxEnt model can make predictions with a high level of accuracy when only 50 data points were included. In comparison with these studies, the present study included 84 data points.

In addition to the environmental variables considered in this study, other variables such as those linked with human intervention, the presence of snail-suitable water vegetation, groundwater quality and socio-economic factors may also be 
relevant influencing variables on the distribution of $F$. hepatica infestation, and were not assessed in the present study. In future work, additional data relating to these factors will be collected and the predictive model expanded in order to improve the accuracy of the predictions.

\section{Conclusion}

The results of this study indicate that meteorological and geographical factors can affect the distribution of $F$. hepatica infestation in sheep in the Qinghai province of Mainland China. Based upon this knowledge, an approach can be applied to design better and more evidence-based planning and detailed surveillance programmes for fascioliasis, involving more efficient use of the limited funding and human resources that are available. The current control strategies used for fascioliasis in Qinghai include using anthelminthics (niclofolan, albendazole, triclabendazole and ivermectin) to expel the parasitic worms from the infested animals, and molluscicides for the elimination of the intermediate snail hosts. Based on the findings of the present study, herdsmen in Qinghai province could enhance the positive effects of these drugs by more timely application, based upon knowledge of which meteorological factors influence infestation rates. Furthermore, the predictions of the model we generated could also help to guide herdsmen towards avoiding the habitat "danger zones" of F. hepatica infestation during the grazing season and to take measures (such as digging drains and transforming swamps) to destroy the living conditions of the intermediate host. It is hoped that the findings will also inform scientific understanding of the risks of $F$. hepatica infestation spreading from one area to another. Further research, involving the collection of more detailed information for a greater number of potentially influential variables, will further improve the ability to predict changes in $F$. hepatica prevalence and distribution in this region of Mainland China.

Acknowledgements. We thank Mr. Wei Li and his team from Qinghai Province University for their work. The authors declare that there are no conflicts of interest.

\section{References}

1. Anderson RP, Peterson AT, Gómez-Laverde M. 2002. Using niche-based GIS modeling to test geographic predictions of competitive exclusion and competitive release in South American pocket mice. Oikos, 93(1), 3-16.

2. Attwood SW, Ibaraki M, Saitoh Y, Nihei N, Janies DA. 2015. Comparative phylogenetic studies on Schistosoma japonicum and its snail intermediate host Oncomelania hupensis: origins, dispersal and coevolution. PLoS Neglected Tropical Diseases, 9(7), e0003935.

3. Charlier J, Sanders M, Vercruysse J. 2009. The direct costs of infections with gastrointestinal nematodes and liver fluke in the Flemish dairy population. Vlaams Diergeneeskundig Tijdschrift, 78(4), 196-200.

4. Chen YY, Huang XB, Xiao Y, Jiang Y, Shan XW, Zhang J, Cai SX, Liu JB. 2014. Spatial analysis of Schistosomiasis in Hubei
Province, China: a GIS-based analysis of Schistosomiasis from 2009 to 2013. PLoS One, 10(4), e0118362.

5. Darrenf W. 2007. Modelling the potential geographic distribution of invasive ant species in New Zealand. Biological Invasions, 9(6), 723-735.

6. Durr PA, Tait N, Lawson AB. 2005. Bayesian hierarchical modelling to enhance the epidemiological value of abattoir surveys for bovine fasciolosis. Preventive Veterinary Medicine, 71(3-4), 157-172.

7. Galaktionov KV, Dobrovolskij AA. 2003. The biology and evolution of Trematodes. Springer: The Netherlands.

8. Gao X, Xiao J, Qin H, Cao Z, Wang H. 2016. Impact of meteorological factors on the prevalence of porcine pasteurellosis in the southcentral of Mainland China. Preventive Veterinary Medicine, 125, 75-81.

9. Hill DE, Dubey JP, Baroch JA, Swafford SR, Fournet VF, Hawkinscooper D, Pyburn DG, Schmit BS, Gamble HR, Pedersen K. 2014. Surveillance of feral swine for Trichinella spp. and Toxoplasma gondii in the USA and host-related factors associated with infection. Veterinary Parasitology, 205(3-4), 653-665.

10. Kendall SB, Mccullough FS. 1951. The emergence of the cercariae of Fasciola hepatica from the snail Limnaea truncatula. Journal of Helminthology, 25(1-2), 77-92.

11. Madsen H, Carabin H, Balolong D, Tallo VL, Olveda R, Yuan M, Mcgarvey ST. 2008. Prevalence of Schistosoma japonicum infection of Oncomelania quadrasi snail colonies in 50 irrigated and rain-fed villages of Samar Province, the Philippines. Acta Tropica, 105(3), 235-241.

12. Martínez-Valladares M, Robles-Pérez D, Martínez-Pérez JM, Cordero-Pérez C, Ma DRF, Fernández-Pato N, González-Lanza C, Castañón-Ordóñez L, Rojo-Vázquez FA. 2013. Prevalence of gastrointestinal nematodes and Fasciola hepatica in sheep in the northwest of Spain: relation to climatic conditions and/or man-made environmental modifications. Parasites \& Vectors, 6, 282.

13. Mas-Coma S, Bargues MD, Valero MA. 2005. Fascioliasis and other plant-borne trematode zoonoses. International Journal for Parasitology, 35(11-12), 1255-1278.

14. Mas-Coma S, Valero MA, Bargues MD. 2009. Climate change effects on trematodiases, with emphasis on zoonotic fascioliasis and schistosomiasis. Veterinary Parasitology, 163(4), 264-280.

15. Mas-Coma S, Valero MA, Bargues MD. 2009. Fasciola, lymnaeids and human fascioliasis, with a global overview on disease transmission, epidemiology, evolutionary genetics, molecular epidemiology and control. Advances in Parasitology, 69, 41-146.

16. Matyukhina DS, Miquelle DG, Murzin AA, Pikunov DG, Fomenko PV, Aramilev VV, Litvinov MN, Salkina GP, Seryodkin IV, Nikolaev IG. 2014. Assessing the influence of environmental parameters on Amur Tiger distribution in the Russian Far East Using a MaxEnt modeling approach. Achievements in the Life Sciences, 8(2), 95-100.

17. Mccann CM, Baylis M, Williams DJL. 2010. The development of linear regression models using environmental variables to explain the spatial distribution of Fasciola hepatica infection in dairy herds in England and Wales. International Journal for Parasitology, 40(9), 1021-1028.

18. Moreno R, Zamora R, Molina JR, Vasquez A, Herrera MÁ. 2011. Predictive modeling of microhabitats for endemic birds in South Chilean temperate forests using Maximum entropy (MaxEnt). Ecological Informatics, 6(6), 364-370. 
19. Novobilský A, Engström A, Sollenberg S, Gustafsson K, Morrison DA, Höglund J. 2014. Transmission patterns of Fasciola hepatica to ruminants in Sweden. Veterinary Parasitology, 203(3-4), 276-286.

20. Ollerenshaw CB. 1971. Some observations on the epidemiology of fascioliasis in relation to the timing of molluscicide applications in the control of the disease. Veterinary Record, $88,152-164$

21. Ollerenshaw CB, Smith LP. 1969. Meteorological factors and forecasts of helminthic disease. Advances in Parasitology, 7, 283-323.

22. Pérez-Creo A, Díaz P, López C, Béjar JP, Martínez-Sernández V, Panadero R, Díez-Baños P, Ubeira FM, Morrondo P. 2015. Fasciola hepatica in goats from north-western Spain: Risk factor analysis using a capture ELISA. Veterinary Journal, 208, 104-105.

23. Peterson AT, Papeş M, Soberón J. 2008. Rethinking receiver operating characteristic analysis applications in ecological niche modeling. Ecological Modelling, 213(1), 63-72.

24. Peterson AT, Sánchez-Cordero V, Martínez-Meyer E, NavarroSigüenza AG. 2006. Tracking population extirpations via melding ecological niche modeling with land-cover information. Ecological Modelling, 195(3-4), 229-236.

25. Phillips SJ, Anderson RP, Schapire RE. 2006. Maximum entropy modeling of species geographic distributions. Ecological Modelling, 190(3-4), 231-259.

26. Phillips SJ, Dudík M. 2008. Modeling of species distributions with MaxEnt: new extensions and a comprehensive evaluation. Ecography, 31(2), 161-175.

27. Poulin R. 2006. Global warming and temperature-mediated increases in cercarial emergence in trematode parasites. Parasitology, 132(Pt 1), 143-151.

28. Rapsch C, Dahinden T, Heinzmann D, Torgerson PR, Braun U, Deplazes P, Hurni L, Bär H, Knubbenschweizer G. 2008. An interactive map to assess the potential spread of Lymnaea truncatula and the free-living stages of Fasciola hepatica in Switzerland. Veterinary Parasitology, 154(3-4), 242-249.

29. Sangwan AK, Jackson B, Glanville WD, Pfeiffer DU, Stevens KB. 2016. Spatial analysis and identification of environmental risk factors affecting the distribution of Indoplanorbis and Lymnaea species in semi-arid and irrigated areas of Haryana, India. Parasite Epidemiology \& Control, 1(3), 252-262.

30. Schweizer G, Braun U, Deplazes P, Torgerson PR. 2005. Estimating the financial losses due to bovine fasciolosis in Switzerland. Veterinary Record, 157(7), 188-193.

31. Stockwell DRB, Peterson AT. 2002. Effects of sample size on accuracy of species distribution models. Ecological Modelling, 148(1), 1-13.

32. Team RC. 2013. R: A language and environment for statistical computing. R Foundation for Statistical Computing, Vienna, Austria.

33. Tognelli MF, Roigjuñent SA, Marvaldi AE, Flores GE, Lobo JM. 2009. An evaluation of methods for modelling distribution of Patagonian insects. Revista Chilena De Historia Natural, $82(3), 347-360$.

34. Torgerson P, Claxton J. 1999. Epidemiology and control, in Fasciolosis. Dalton JP, Editor. CABI Publishing, Utrecht, Netherlands. p. 113-149.

35. Tum S, Puotinen ML, Copeman DB. 2004. A geographic information systems model for mapping risk of fasciolosis in cattle and buffaloes in Cambodia. Veterinary Parasitology, 122(2), 141-149.

36. Yuan HS, Wei YL, Wang XG. 2015. Maxent modeling for predicting the potential distribution of Sanghuang, an important group of medicinal fungi in China. Fungal Ecology, 17, 140-145.

37. Zhao X, Cao M, Feng HH, Fan H, Chen F, Feng Z, Li X, Zhou $\mathrm{XH}$. 2014. Japanese encephalitis risk and contextual risk factors in Southwest China: A Bayesian hierarchical spatial and spatiotemporal analysis. International Journal of Environmental Research \& Public Health, 11(4), 4201-4217.

Cite this article as: Qin H, Gao X, Wang H \& Xiao J: Relative importance of meteorological and geographical factors in the distribution of Fasciola hepatica infestation in farmed sheep in Qinghai province, China. Parasite, 2016, 23, 59.

Reviews, articles and short notes may be submitted. Fields include, but are not limited to: general, medical and veterinary parasitology; morphology, including ultrastructure; parasite systematics, including entomology, acarology, helminthology and protistology, and molecular analyses; molecular biology and biochemistry; immunology of parasitic diseases; host-parasite relationships; ecology and life history of parasites; epidemiology; therapeutics; new diagnostic tools.

All papers in Parasite are published in English. Manuscripts should have a broad interest and must not have been published or submitted elsewhere. No limit is imposed on the length of manuscripts.

Parasite (open-access) continues Parasite (print and online editions, 1994-2012) and Annales de Parasitologie Humaine et Comparée (1923-1993) and is the official journal of the Société Française de Parasitologie. 